18. Graham S, Brookey J. Do patients understand? Perm J 2008; 12: 67-69.

19. Parikh N S, Parker R M, Nurss J R, Baker D W, Williams $M V$. Shame and health literacy: the unspoken connection. Patient Educ Couns 1996; 27: 33-39.

20. Easton P, Entwistle V A, Williams B. How the stigma of low literacy can impair patient-professional spoken interactions and affect health: insights from a qualitative investigation. BMC Health Serv Res 2013; 13: 319

21. Cooke M W, Wilson S, Cox P. Public understanding of medical terminology: non-English speakers may not receive optimal care. Emerg Med J 2000; 17: 119-121.

22. Kessels R P. Patients' memory for medical information. J R Soc Med 2003; 96: 219-222.

23. Misra S, Daly B, Dunne S, Millar B, Packer M Asimakopoulou K. Dentist-patient communication: what do patients and dentists remember following a consultation? Implications for patient compliance. Patient Prefer Adher 2013: 7: 543-549.

24. Ley P. Communicating with patients: Improving communication, satisfaction and compliance. New York: Croom Helm, 1988

25. Lapakko D. Communication is $93 \%$ Nonverbal: An Urban Legend Proliferates. Commun Theatre Assoc Minn J 2007; 34: 7-19.

26. Mehrabian A, Ferris S R. Inference of attitudes from nonverbal communication in two channels. J Consult Psychol 1967; 31: 248-252.

27. Healthcare Improvement Scotland. Supporting personcentred care in COVID-19 situations. 2020. Available at https://ihub.scot/improvement-programmes/peopleled-care/person-centred-health-and-care/supportingperson-centred-care-in-covid-19-situations/ (accessed June 2020).

28. Marra A, Buonanno P, Vargas M. How COVID-19 pandemic changed our communication with families: losing nonverbal cues. Crit Care 2020; 24: 297.

29. O'Reilly M, Cahill M R, Perry I J. Writing to patients: a randomised controlled trial. Clin Med 2006; 6: 178-182.

30. NHS Digital service manual. Content style guide. 2019. Available at https://service-manual.nhs.uk/content (accessed May 2020).

31. Hong Y, Ehlers K, Gillis R, Patrick T, Zhang J. A usability study of patient-friendly terminology in an EMR system. Stud Health Technol Inform 2010; 160(Pt 1): $136-140$.

32. Ellis A, Fry R. Regional health inequalities in England. Reg Trends 2010; 42: 60-79.

33. Coats R O, Crossley K L, Conlin N et al. Cognitive and sensorimotor function in participants being treated for trigeminal neuralgia pain. J Headache Pain 2020 21: 91.

\title{
Correction to: Research: Patient and clinician satisfaction with video consultations in dentistry - part one: patient satisfaction
}

The original article can be found online at https://doi.org/10.1038/s41415-021-3007-y.

Author's correction note:

Research article Br Dent J 2021; https://doi.org/10.1038/s41415-021-3007-y

When this article was initially published the Acknowledgements were not included. The Acknowledgements section should have read:

The authors would like to thank: Julia Radecki, Renu George, Sara Stephens and Varlie Bacon for their assistance with this project.

The journal apologises for any inconvenience caused.

\section{Correction to: Research: Patient and clinician satisfaction with video consultations in dentistry - part two: clinician satisfaction}

The original article can be found online at https://doi.org/10.1038/s41415-021-3009-9.

Author's correction note:

Research article Br Dent J 2021; https://doi.org/10.1038/s41415-021-3009-9

When this article was initially published the Acknowledgements were not included. The Acknowledgements section should have read:

The authors would like to thank: Julia Radecki, Renu George, Sara Stephens and Varlie Bacon for their assistance with this project.

The journal apologises for any inconvenience caused. 